\title{
Industrial Water Mass Balance Analysis
}

\author{
Pham Thi Thuy, Pham Thanh Tuan, and Nguyen Manh Khai
}

\begin{abstract}
Industry is demanding ever-greater volumes of water, while at the same time producing wastes and effluents, which in many places taint and damage the quality of this precious resource on which all life depends. The water balance of industrial parks is not well known. This article formalizes a systematic water mass balance framework to quantify water flows into, water flows inside and effluents out of the industrial park. Using the method, Long Thanh industrial park in Dong Nai province, Vietnam was evaluated. The approach makes visible large flows of water that have previously been unaccounted and ignored. In 2012-2014, the industrial parks varied 28 to $53 \%$ for water consumption for production, 40 to $45 \%$ for effluent discharge. The approach demonstrates how the principles of water balance can help robust water accounting, monitoring, optimum operating and management in industrial park.
\end{abstract}

Index Terms-Mass balance, industrial water, water balance analysis.

\section{INTRODUCTION}

Industry is demanding ever-greater volumes of water, while at the same time producing wastes and effluents. The industrial activities, however, can lead to severe pollution and resource depletion, especially water pollution and water depletion, because many industrial parks are located along the rivers for convenient water use and transport [1]. The increasing demands for water supply and deteriorated water quality have been important constraints to the sustainable development of industrial parks in developing countries like Vietnam. Industrial-scale wastewater reuse, wastewater treatment and decentralized supplies are a reliable and practical way to cope with these problems. This trend creates an enhanced need to understand water flows and water balance within the industrial park boundary.

A mass-balance approach is useful in examining the water balance in the industrial parks. Transformation refers to alteration of mass water (the state in which the mass water is transported) from inflow to outflow waters, without changing the total mass water that entered the system [2]. However, this approach has not yet been applied in developing countries because of poor data availability and quality. Hence, the paper describes the industrial water mass balance analysis in Long Thanh industrial parks, Dong Nai province, Vietnam, in

Manuscript received February 14, 2015; revised June 1, 2015. This work was supported in part by the Vietnam Environment Administration, Dong Nai Industrial Park Management Broad, and Hanoi University of Science Vietnam National University.

Pham Thi Thuy and Nguyen Manh Khai are with the Faculty of Environmental Science, Hanoi University of Science, Vietnam National University, 334 Nguyen Trai, Hanoi, Vietnam (e-mail: phamthithuy@hus.edu.vn, khainm@gmail.com).

Pham Thanh Tuan is with Vietnam Environment Administration, 10 Ton That Thuyet, Hanoi, Vietnam (e-mail: phamthanhtuantd@gmail.com). contribution the better understanding of water metabolism in industrial park.

\section{Methodologies}

\section{A. Case Study}

Long Thanh industrial park established since October, 2003 in Dong Nai province, Vietnam; that has area of 486.91ha, 111 enterprises with 12,581 workers, operated rate of $79 \%$. The formation and development of industrial zones in Dong Nai province in recent years has contributed to promoting the industry and economic growth as well as accelerate process of economic restructuring towards industrialization and modernization, and also create jobs for workers throughout the country. However, water management is faced number of problems such as 1) inaccurate forecast of water quantity, 2) technical design of wastewater treatment plant inconsistent with the capacity, 3) limitation in operation and maintenance of drainage system and wastewater treatment plant, 4) limitation in water management at local level. Hence, the main objective of this case study was to examine the water metabolism of the industrial park using water balance analysis.

\section{B. Data Acquisition}

A questionnaire survey on water use in industrial parks was conducted through Long Thanh industrial zone. The detailed water balance was examined. Data on volumes of water consumed and effluent generated was obtained from the industrial park records.

The acquisition of data for the case study was done through a questionnaire-survey, expressly developed for the project. The inquiries contained 14 questions, grouped into four blocks:

- Company organization: economic activity, environmental policy and organization, description of the production processes;

- Water consumption: sources and flows;

- Water service: water supply, connection of drainage system;

- Wastewater production: composition, flows and treatments.

Questionnaires were hand-delivered and later gathered from each company in Long Thanh industrial park. In some cases, the information was completed with face-to-face or telephone interviews. Matric for water balance analysis was constructed using inquiry data. Each row of the matric represented a company, while each column represented a component of water balance analysis (ie., water consumption, wastewater generation, wastewater treated, water losses, etc.). Several problems arose while revising the inquiries data: some companies had not fully completed the questionnaires, 
so there were many unknown flows; much erroneous data were also found. Water balance was applied to each company in order to verify the data (find the erroneous values) and to quantify unknown water flows. After applying this methodology, 7 companies were discarded because of the incongruity in the data given, and the final analysis was done for 94 companies.

\section{Mass Balance Analysis}

The industrial water use survey was carried resulting in creation of water flow balances. In order to systematize the study the method of mass balance analysis was applied. The water balance approach where, based on conservation of mass, the sum of inflows must equal the sum of outflows plus any change in storage. An initial and critical step is to define a water balance domain by specifying spatial and temporal boundaries of the industrial park.

Conceptually, the water balance approach is straightforward, though many of the components of the water balance cannot be directly measured or are difficult to estimate. In spite of the limitations, experience has shown that even gross estimates of water balances can be quite useful to water managers and researchers [3]. Water balances have been used successfully to study water use and productivity at the basin level [4], at the irrigation service level [5], at the field level [6], at the urban system [2], at industrial process [7]-[9], that use to provide early recognition of changes in quantity and quality of water. Often, first-order estimates provide the basis for more in-depth analysis that provides important clues on increasing water productivity.

\section{RESULT AND DISCUSSION}

\section{A. Current Water Use in Long Thanh Industrial Park}

The summary of industrial sector of the companies was given in Fig. 1. The industrial sectors of the enterprises in industrial parks in Dong Nai province were divided into 10 groups, such as food \& beverage processing, chemical industry, textiles \& leather, mechanical industry \& metal product, gas products, electronic equipment, paper \& wood products, tile products, cosmetic, plastic products, construction materials and other. The food \& beverage processing, textiles \& leather, mechanical industry \& metal product made up high portion of industrial sector in Long Thanh industrial park.

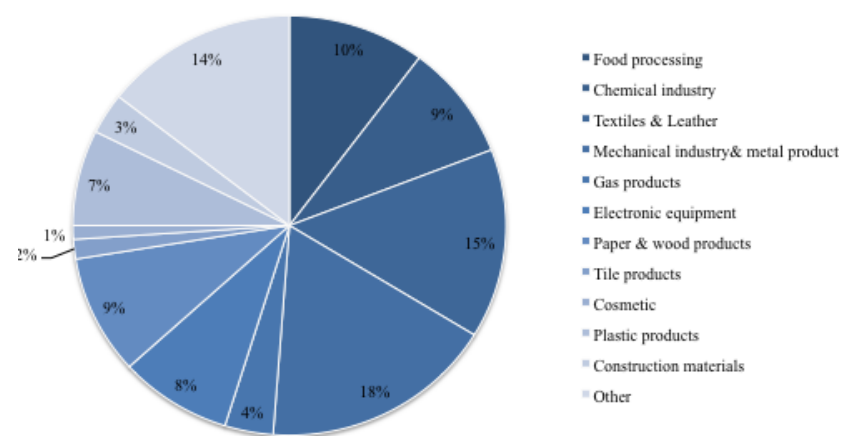

Fig. 1. Portion of industrial sector in Long Thanh industrial park.

In industrial park, water use is widely used for various activities (expressed in Fig. 2), such as: 1) Production processes such as incorporation in the final product, washing or rinsing of raw materials or final products, etc.; 2) Auxiliary processes such as preparation of solvents or slurries, cleaning of equipment and space, removing or providing heat, etc.; 3) Domestic use such as meeting hygienic and domestic needs; 4) Outdoor use such as irrigation of landscape space. Water losses volume can be appeared through evaporation, drainage, condensation or losses during production and auxiliary processes.

In Long Thanh industrial park, entire enterprises use piped water supply, which provided by Nhon Trach Water Supply Company. Wastewater generated from 2 main sources: manufacturing process and domestic use. Currently, the sewage system of the entire 111 enterprises operating have been directly connected to the centralize wastewater treatment plant with capacity $15,000 \mathrm{~m}^{3} /$ day.

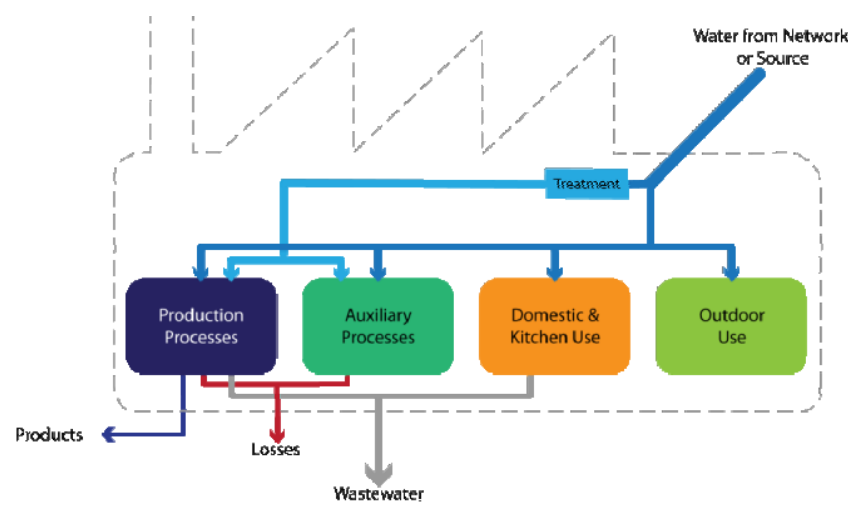

Fig. 2. Water use in industrial park.

\section{B. Mass Balance and Industrial Water}

The key concept of a mass balance is that it accounts for all water movement through in a defined volume in area of industrial park. Mass and volumetric balances are based on principles of conservation of mass and energy over time. An important aspect of mass balance theory is that a powerful cross - check can be undertaken through comparison of the independently measureable quantities of system 1) inputs minus outputs and 2) change in stored water.

Equation (1) summarizes the water mass balance for industrial park, with boundary (B)

$$
\Delta S=Q_{i}-Q_{o}
$$

Here, $\Delta S$ is the change in stored water volume (or mass) within the boundary, $Q_{i}$ is total volume of inputs, $Q_{o}$ is total volume of outputs.

In this paper the system boundary (B) was defined as the area of the industrial park in above industrial facilities. Bulk surface water storage located outside industrial parks and ground water aquifers beneath in these areas were not considered as part of the system. Similarly, inflows to and outflows from the industrial parks via natural rivers and creeks (i.e., flow originating outside industrial park) were excluded from the boundary. Because our intention was to understand how water use in industrial parks in regard to their exchange of water with "the environment".

The water, which is consumed by industry, is therefore the water that evaporates, as well as the water that remains in the product, the byproducts or the solid waste generated. The 
balance of the water is discharged after use as wastewater or effluent. This is why the total withdrawal of water by industry from surface and groundwater is often much more than the water, which is actually consumed. Base on the breakdown of water use in industry, the water balance of an industrial park is described in (2).

$$
I=C+E
$$

where: $I$ is the water withdrawal by industry, $C$ is the water consumption by industry, $E$ is the industrial effluent discharge.

The water withdraw by industry (I), which can be considered as water inflow, is equal to the total of water supply (WS) and water reuse (Re) in industrial park. Reuse within the industrial parks is challenging to define because these volumes were relatively and the boundary not well developed; reuse volumes during production process were not documented and considered internal to the water use for production process. Hence, the wastewater reuse (Re) is defined the treated wastewater reusing for outdoor use (water the plant and clean up the road) within industrial park.

The water consumption by industry $(\mathrm{C})$, which is stored water volume, includes total of water in production process (P), water for domestic use (D) and water losses (L). The water losses (L) can appear during production process, evaporation, leackage from water supply network, effluent discharge not connect to drainage system in industrial park. A similar philosophy as water reuse during production process was adopted with regard to water losses in production process, evaporation, water supply piped network leackage and could be neglected; hence, the water losses (L) is only wastewater not discharge to drainage system within industrial park.

The industrial effluent discharge $(\mathrm{E})$ is the water outflow or effluent discharges from centralize wastewater treatment plant in industrial park.

A number of other water flows could also be discussed in this model but were ignored. For example, some water enters or leaves industrial parks in the form of products, such as raw materials of food processing, drink, bottle water and the juice of fruit for domestic use are examples. This amount was assumed insignificant in the industrial parks studied. This volume of water should not be confused with much larger "virtual water" flows through the industrial parks, which related to the water need needed to produce a product. Only the actual water in the product ( $a \mathrm{H}_{2} \mathrm{O}$ molecules) is included in a water mass balance. Some terms are interdependent. For example, centralized water supply (WS) and rainwater influences wastewater generated. It is logical that the input affects the output; however, the greatest error when one input affects another input. Until a relationship can be derived between rainfall and decentralized water sourced from each industrial park in question, this cannot be addressed quantitatively, only highlighted as an assumption. These interdependencies were judged insignificant for this analysis.

\section{Water Balance Analysis}

Guided by (2), the water balances analysis for industrial parks was used the following steps: 1) system selection, 2) water balance data compilation, estimation, or estimation, or modeling; and 3) performance indicator analysis.

\section{1) System selection}

The system boundary adopted was the industrial park footprint. The areal extent of the system boundary for Long Thanh industrial park was adopted from Dong Nai Industrial Park Management Broad report [10]. This include land for purposes such as manufacturing, internal transport, wastewater treatment, centralized water supply, car parking.

2) Water balance data compilation, estimation, and modeling

The time period 2012-2014 was adopted due to data availability. Data for the area of the industrial parks (A), number of workers, and all parameters of (2) were assembled from public and environmental monitoring reports, research reports, survey form and estimation (Table I).

TABLE I: WATER BALANCE OF LONG THANH INDUSTRIAL PARK (2012-2013)

\begin{tabular}{|c|c|c|c|c|c|c|}
\hline \multirow[b]{2}{*}{ IS } & \multirow{2}{*}{ Number of workers (per.) } & \multirow{2}{*}{ Number of enterprise } & \multirow{2}{*}{ I (m3/day) } & \multirow{2}{*}{$\mathrm{E}$ (m3/day) } & \multicolumn{2}{|c|}{$\mathrm{C}$ (m3/day) } \\
\hline & & & & & for domestic (m3/day) & for production (m3/day) \\
\hline FP & 781 & 10 & 805 & 358 & 94 & 354 \\
\hline $\mathrm{CI}$ & 185 & 6 & 247 & 110 & 22 & 115 \\
\hline $\mathrm{TL}$ & 3803 & 23 & 16284 & 7237 & 456 & 8590 \\
\hline MI & 605 & 11 & 269 & 120 & 73 & 77 \\
\hline $\mathrm{EE}$ & 2840 & 9 & 1276 & 567 & 341 & 368 \\
\hline $\mathrm{Co}$ & 55 & 2 & 27 & 12 & 7 & 8 \\
\hline $\mathrm{PP}$ & 450 & 13 & 256 & 114 & 54 & 88 \\
\hline $\mathrm{CM}$ & 200 & 6 & 87 & 39 & 24 & 25 \\
\hline $\mathrm{O}$ & 1216 & 14 & 532 & 236 & 146 & 149 \\
\hline
\end{tabular}

IS - Industrial sector, FP - Food processing, CI - Chemical industry, TL - Textiles \& Leather, MI - Mechanical industry and metal product, EE - Electronic equipment, Co - Cosmetic, PP - Plastic products, CM - Construction materials, $\mathrm{O}$ - Other, I is the water withdrawal by industry, $\mathrm{C}$ is the water consumption by industry, $\mathrm{E}$ is the industrial effluent discharge.

Water withdrawal, water consumption and effluent discharge from different industrial sectors, in Long Thanh industrial park, in cubic meter per day, is given in Table I; and the result of water mass balance in long Thanh industrial park 
is represented in Fig. 3. The average of water withdrawal from Long Thanh industrial park is $22287 \mathrm{~m}^{3} /$ day, in which textile $\&$ leather with 23 enterprises used highest amount of water, made up $15 \%$ proportion of total water withdraw of industrial park $\left(16,284 \mathrm{~m}^{3} /\right.$ day). By analyzing water consumption and comparing it with effluent discharge, it can be observed that the water consumption in production process in industrial park made up $28-53 \%$ of industrial water withdraw, and the effluent discharge made up 40-45\% of. This is directly related to industrial products and industrial sectors within industrial park; the industrial sectors, which had products also contain water (such as brewery, soft drink bottle, chemical... products), will have water consumption higher than effluent discharge [8]. In Long Thanh industrial park, the food processing, textiles \& leather, chemical industry made up the high portion of industrial sectors, which contain high water consumption in products and the production processes need high water consumption. Hence, the average water consumption in this industrial zone was $49 \%$ higher than the effluent discharge.

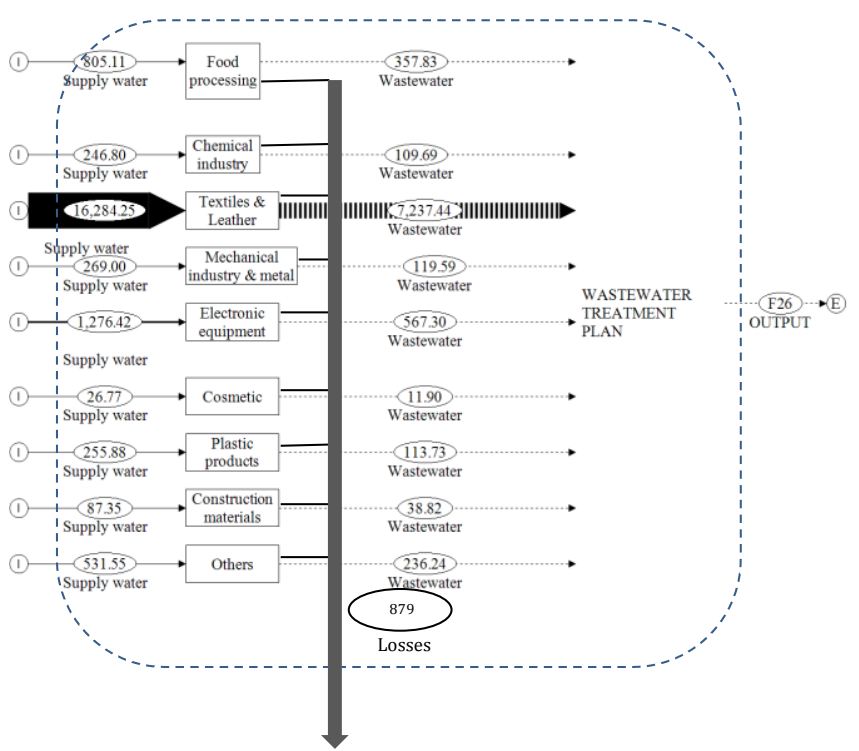

Fig. 3. Water balance analysis in Long Thanh industrial park.

In fact, the water consumption of most industrial sectors was less than effluent discharge, supposes less 10-16\% of effluent discharge. Only the food processing, chemical industry, textiles \& leather have the water consumption higher or nearly equal the effluent discharge. The results demonstrate that this industrial park is not currently well designed to take advantages of water consumption. Thus, implementing improvement strategies in the industrial park is essential in order to decrease the system's water consumption. Strategies focused on minimization and reutilization will suppose a diminution of the water consumption of industrial park or each enterprise; whereas in the case of a substitution of water imported by an industrial park's own resources (i.e. use of rain and ground water), water consumption will remain constant, but the domestic/imported water relation will increase. Thus, the industrial products and industrial sectors, production processes are the important focus of water consumption and effluence discharge. Practically, however, many factors limit how much of such water can actually be used, reuse and losses in production process. These factors include desired water use and quantities, technologies current industrial parks configuration, and the availability of appropriate storage sites [2]. Nonetheless, awareness of these volumes is a first step toward designing and evaluating future industrial parks that draw less on the environment and expect less the environment to assimilate waste.

\section{CONCLUSION}

In spite of poor data availability and quality the water balance analysis and its mathematical formulation can be applied as an instrument for the early recognition of environmentally relevant material flux changes in Vietnam. The Long Thanh industrial park studied varied with regard to their potential for water consumption for production and effluent discharge to meet total water demand (28-53\% for water consumption for production, $40-45 \%$ for effluent discharge). The approach demonstrates that the industrial park is not currently well designed to take advantages of water consumption. Thus, implementing improvement strategies focused on minimization and reutilization will suppose a diminution of the water consumption of industrial park or each enterprise; whereas in the case of a substitution of water imported by an industrial park's own resources.

\section{ACKNOWLEDGMENT}

The authors are very thankful to the Vietnam Environment Administration and Dong Nai Industrial Park Management Parks for supporting in data collection. The authors also thank to Hanoi University of Science for partly providing financial assistance through a university project.

\section{REFERENCES}

[1] Z. Yuan, W. Jiang, and J. Bi, "Cost-effectiveness of two operational models at industrial wastewater treatment plants in China: A case study in Shengze town, Suzhou City," Journal of Environment Management, vol. 91, pp. 2038-2044, 2010.

[2] K. Steven, G. Alan, and M. Joseph, "Urban water mass balance analysis," Journal of Industrial Ecology, vol. 15, no. 5, pp. 693-706, 2011.

[3] M. David and R. Sakthivadivel, "Water accounting to assess use and productivity of water," International Journal of Water Resources Development, vol. 15 , no. 1/2, pp. 55-71, 1999.

[4] G. Z. Hassan and M. N. Bhutta, "A water balance model to estimate groundwater recharge in Rechna Doab, Pakistan," Irrigation and Drainage Systems, vol. 10, pp. 297-317, 1996.

[5] C. J. Kijne, "Water and salt balances for iirrigated agriculture in Pakistan," Research Report 6, Colombo, Sri Lanka, International Irrigation Management Institute, pp. 12-15, 1996.

[6] T. P. Tuong, R. J. Cabangon, and M. C. S. Wopereis, "Quantifying flow processes during land soaking of cracked rice soils," Soil Science Society of America Journal, vol. 60, no. 3, pp. 223-230, 1996.

[7] C. Binder, R. Schertenleib, J. Diaz, H. P. Bader, and P. Baccini, "Regional water balance as a tool for water management in developing countries," Water Resources Development, vol. 13, no. 1, pp. 5-20, 1997.

[8] S. Cristina, G. Xavier, and V. Teresa, "Material flow analysis adapted to an industrial area," Journal of Cleaner Production, vol. 15, pp. 1706-1715, 2007.

[9] G. Bekithemba, M. Sipho, B. Jeff, and L. Darren, "Industrial water demand management and cleaner production potential: A case of three industries in Bulawayo, Zimbabwe," Physics and Chemistry of the Earth, vol. 28, pp. 797-804, 2003.

[10] DONRE (Dong Nai Department of Natural Resource and Environment), “Annual report on environmental impact assessment of industrial parks in Dong Nai," 2014. 


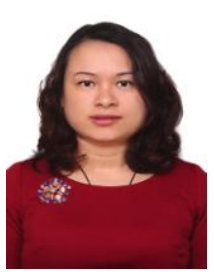

Pham Thi Thuy is an environmental engineer. She received a $\mathrm{PhD}$ in water management and treatment from Katholieke University of Leuven in 2012. Subsequently, she worked as a consultant and researcher for both the public and the private sectors in Vietnam. Her scientific contribution in the field of water treatment and water management was recognised by the Young Scientist Award by MABUNESCO in the year 2008. Dr. Pham Thi Thuy is currently employed by Falculty of Environmental Science, Hanoi University of Science, Vietnam National University.

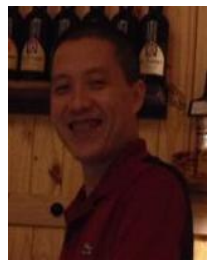

Pham Thanh Tuan is an environmental scientist. He received his master degree in environmental science from Hanoi University of Science in 2003. He has worked for the Department of Environmental Impact Assessment and Appraisal, Vietnam Environment Administration since 2000. He also has rich experience on water management, especially industrial water management in Vietnam.

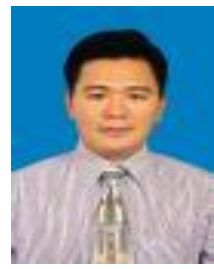

Nguyen Manh Khai is an environmental scientist. He received his $\mathrm{PhD}$ in environmental chemistry in Agricultural University in Sweden in 2007. He worked as a researcher and lecturer in Falculty of Environmenta Science, Hanoi University of Science, Vietnam National University. He was a team leader in many environmental management and environemental treatment projects in Vietnam. 